\title{
Aproveitamento de escória de siderurgia em substratos alternativos para produção de mudas de pimenteira Dedo-de-moça
}

\author{
Eduardo France Oza ${ }^{1}$, Paola Alfonsa Vieira Lo Monaco ${ }^{1}$, Millena Monteiro dos Santos ${ }^{1}$, Thiago Lopes Rosado ${ }^{1}$, \\ Marcelo Rodrigo Krause ${ }^{1}$, Willian Alves Garcia ${ }^{1}$
}

$10.1590 / 0034-737 X 201865010014$

\section{RESUMO}

Estudos relacionados com o aproveitamento de escória de siderurgia tornaram-se imprescindíveis, pela possibilidade de seu uso como componente de substratos na produção de mudas e por esse uso minimizar o risco de contaminação ambiental, decorrente do descarte inadequado. Assim, objetivou-se, com este trabalho, avaliar o efeito de níveis crescentes de escória de siderurgia em substratos, compostos por solo com esterco bovino curtido e areia, nas variáveis de crescimento e na qualidade de mudas de pimenteira dedo-de-moça (Capsicum baccatum L.). Utilizou-se o delineamento em blocos casualizados, tendo como tratamentos cinco concentrações de escória $(0 \% ; 2,5 \% ; 5 \% ; 10 \%$ e; $20 \%)$ e quatro repetições. As avaliações ocorreram aos 55 dias após semeadura, consistindo na contagem do número de folhas, na medição da altura de planta e do diâmetro do coleto, na quantificação das massas secas de folhas e raízes da planta e na determinação do Índice de Qualidade de Dickson. Modelos de regressão foram ajustados $(\mathrm{P}<0,05)$ aos tratamentos com níveis crescentes de escória de siderurgia. A adição em torno de $10 \%$ de escória ao substrato proporcionou os maiores valores das variáveis de crescimento, em mudas de pimenteira Dedo-de-moça.

Palavras-chave: Capsicum baccatum L; resíduo de siderurgia; substrato.

\section{ABSTRACT}

\section{Use of basic slag in alternative substrates for the production of 'Dedo-de-moça' hot pepper seedlings}

Studies related to the use of basic slag have become essential due to the possibility of use as a component of substrates in the production of seedlings and to minimize the risk of environmental contamination due to inadequate disposal. The objective of this research was to evaluate the effect of increasing levels of basic slag in substrates composed of soil, bovine manure, and sand on growth variables and quality of "Dedo de moça" pepper plants (Capsicum baccatum L.). A randomized block design was used, with five treatments of basic slag (0, 2.5, 5, 10, and 20\%) and four replicates as treatments. The evaluations occurred at 55 days after sowing, consisting of counting the number of leaves, measuring plant height and stem diameter, and quantifying shoot and root dry masses. Regression models were adjusted $(\mathrm{P}<0.05)$ in the treatments with increasing levels of basic slag. The addition of about $10 \%$ of basic slag in the substrate provided the highest values of growth variables in Dedo de moça pepper plants.

Key words: Capsicum baccatum L; waste; substrate; basic slag.

Submetido em 08/08/2017 e aprovado em 21/02/2018.

'Instituto Federal do Espírito Santo, Santa Teresa, Espírito Santo, Brasil. eduardo.franceoza@hotmail.com; paolalm@ifes.edu.br; millena_monteiro@hotmail.com; thiagolr@ifes.edu.br; agrokrause@gmail.com; willianagron@gmail.com

*Autor para correspondência: eduardo.franceoza@hotmail.com 


\section{INTRODUÇÃO}

As pimenteiras são agronomicamente classificadas como olerícolas, pertencentes à família Solanaceae, do gênero Capsicum. Dentre as mais conhecidas e cultivadas no Brasil, destacam-se as pimentas Capsicum frutescens L. Ruiz \& Pav. (pimenta malagueta) e Capsicum baccatum L. Ruíz \& Pav. (Dedo-de-moça) (Filgueira, 2008). Em razão da elevada capacidade de geração de emprego e renda, principalmente para os pequenos produtores, as pimentas do gênero Capsicum posicionam-se dentro da agricultura brasileira como culturas de elevada importância socioeconômica.

A pimenta Dedo-de-moça é comumente utilizada no processo de fabricação de molhos, no uso medicinal, em razão dos diversos componentes com propriedades farmacológicas, e como plantas ornamentais, por seu porte anão e por seus frutos com diferentes cores no processo de maturação.

O sucesso do desempenho das plantas no campo está diretamente ligado à qualidade das mudas, sendo a escolha do substrato um fator primordial para resultado final satisfatório

Para Freitas et al. (2013), o sistema de produção é altamente dependente da utilização de substratos comerciais, tornando onerosa a produção de mudas no Brasil. Por essa razão, tem-se buscado materiais alternativos aos substratos comerciais, aproveitando-se resíduos agrícolas e industriais na composição de substratos, como forma de minimizar os custos de produção, bem como promover maior qualidade de mudas. Além disso, Neves et al. (2010) ressaltam que o aproveitamento de resíduos na formulação de substratos vem-se tornando uma prática agrícola de caráter sustentável, pois busca minimizar o impacto ambiental que seria provocado pela disposição inadequada desses resíduos.

Dentre os resíduos industriais gerados em elevada quantidade, e com potencial para componentes de substratos, destaca-se a escória de siderurgia. De acordo com Prezoti \& Martins (2012), as escórias de siderurgia podem ser consideradas importantes opções, uma vez que apresentam compostos neutralizantes da acidez do solo, como silicatos, e nutrientes, como o cálcio, o magnésio e o fósforo, dentre outros. Prado \& Natale (2004) afirmam que a escória de siderurgia apresenta efeito corretivo e fertilizante, podendo melhorar a fertilidade de solos que são utilizados como substratos para produção de mudas os quais, muitas vezes, são de baixa fertilidade. Assim, a melhoria das propriedades químicas do substrato poderá beneficiar a nutrição das plantas e, consequentemente, a qualidade das mudas. Os mesmos autores reforçam que a resposta da cultura à aplicação da escória de siderurgia é dependente da espécie vegetal e do tipo de resíduo siderúrgico, ou seja, se é uma escória gerada em siderurgias de alto forno, de aciaria ou ferrocromo. De acordo com Pinto Júnior et al. (2011), a escória de aciaria possui relação de $\mathrm{CaO} / \mathrm{SiO}_{2}$ (em torno de 4,6), superior à da escória de alto forno, que segundo Rossa \& Portela (2012) é de 1,05 a 1,18 , e à da escória de ferrocromo, que, de acordo com Prado \& Natale (2004), é de 0,9.

Caetano et al. (2016) reforçam que, apesar de as escórias conterem metais pesados, a aplicação de doses até 10 t ha ${ }^{-1}$ no solo não resulta em teores superiores aos considerados críticos para agricultura. Além disso, segundo os mesmos autores, as concentrações de metais pesados encontrados na matéria seca de plantas de milho submetidas à aplicação do resíduo foram inferiores às dos níveis críticos de toxicidade desses elementos, para a maioria das plantas.

Em razão dessas características, o emprego de escórias industriais como componente de substratos tem sido estudado por alguns autores, como Prado et al. (2003), utilizando escória de aciaria para mudas de goiabeira; Prado \& Natale (2004), utilizando escória de ferrocromo na produção de mudas de maracujazeiro e Santos et al. (2011), utilizando escória de alto forno na produção de mudas de paricá. Quanto ao efeito desse resíduo na qualidade de mudas de pimenteira Dedo-de-moça, não há qualquer estudo para fundamentar seu uso como componente de substrato. No entanto, considera-se a hipótese de que a escória de siderurgia de aciaria é um importante componente no substrato como fonte de nutrientes, especialmente o cálcio, numa proporção adequada, que carece de confirmação da experimentação. Desse modo, objetivou-se, com a realização deste trabalho, avaliar o efeito de níveis crescentes de escória de siderurgia de aciaria, em substrato composto por solo com esterco bovino curtido e areia, nas variáveis de crescimento e na qualidade de mudas de pimenteira Dedo-de-moça (Capsicum baccatum L.).

\section{MATERIAIS E MÉTODOS}

O experimento foi implantado e conduzido no viveiro de produção de mudas do Ifes - Campus Santa Teresa, no município de Santa Teresa, Espírito Santo ( $18^{\circ} 48^{\prime} \mathrm{S} ; 40^{\circ} 40^{\prime}$ O; $130 \mathrm{~m}$ de altitude). O clima, segundo a classificação de Köppen, enquadra-se no tipo Cwa (subtropical de inverno seco), com temperatura média anual de $24,6{ }^{\circ} \mathrm{C}$ e precipitação anual variando entre 700 a $1200 \mathrm{~mm}$. A temperatura e a umidade relativa do ar no período experimental variaram entre 18,5 a $39,2{ }^{\circ} \mathrm{Ce} 54,85$ a $90,22 \%$, respectivamente.

$\mathrm{O}$ viveiro onde foi desenvolvido o trabalho era coberto com tela de propileno, com redução da radiação solar em $50 \%$.

Como substrato, utilizou-se uma mistura de solo estéril (corrigido com calcário), esterco bovino curtido e areia, na 
proporção 3:1:1, completamente homogeneizado. Em seguida, a mistura foi submetida ao peneiramento para eliminação de torrões que poderiam prejudicar o desenvolvimento das plântulas.

O solo utilizado é classificado como Latossolo Vermelho-Amarelo distrófico, textura média, extraído do horizonte B. O esterco bovino curtido foi obtido do setor de Bovinocultura do próprio campus.

A escória utilizada no experimento foi obtida na forma de pó, em uma indústria siderúrgica de aciaria, localizada em Vitória, ES.

Como modelo experimental, foi adotado o delineamento em blocos casualizados, cujos tratamentos foram constituídos de cinco níveis crescentes de escória de siderurgia $(0 \%, 2,5 \%, 5 \%, 10 \%$ e $20 \%)$, adicionada em substrato composto por uma mistura de solo, esterco e areia (3:1:1), com base no volume, com quatro repetições, com 25 plantas cada, totalizando 500 plantas. Foram consideradas úteis cinco plantas para cada unidade experimental, resultando na avaliação de 20 plantas por tratamento.

Amostras homogêneas dos substratos com os respectivos níveis de escória de siderurgia (tratamentos) foram coletadas e encaminhadas ao Laboratório de Análise de Solos do Instituto Federal do Espírito Santo - campus Itapina, para a determinação dos atributos químicos, apresentados na Tabela 1.

Utilizou-se o sistema de produção de mudas em bandejas suspensas, alocadas em bancadas de alvenaria, com tubetes de $500 \mathrm{~mL}$. A adição das concentrações de escória ao substrato ocorreu sete dias antes da semeadura, sendo esta realizada com densidade de uma semente por tubete a uma profundidade de $1,0 \mathrm{~cm}$.

As sementes utilizadas foram do gênero Capsicum, espécie Capsicum baccatum var. pendulum (Wild) Eshbaugh, conhecida como Dedo-de-moça.

A irrigação foi realizada manualmente, de três a cinco vezes por dia. Não se aplicaram quaisquer tipos de defensivos agrícolas nem, tampouco, foi realizado nenhum outro processo de correção nos substratos.
As avaliações ocorreram aos 55 dias após semeadura, durante os meses de dezembro de 2016 e janeiro de 2017 , consistindo na contagem do número de folhas, na medição da altura de planta e do diâmetro do coleto, na quantificação das massas secas de folhas e raízes da planta e na determinação do Índice de Qualidade de Dickson (IQD).

Para a obtenção da altura da parte aérea, foi utilizada uma régua milimetrada, medindo-se da base do caule até a gema apical que deu origem à última folha. $\mathrm{O}$ diâmetro do coleto foi obtido com paquímetro digital de precisão. A massa seca da parte aérea foi obtida por meio do corte das mudas na altura do coleto. Para a obtenção da massa seca radicular, as raízes foram cuidadosamente lavadas em água corrente, sobre peneira com abertura de $5 \mathrm{~mm}$. Posteriormente, os materiais foram acondicionados em sacos de papel e alocados em estufa com circulação de ar forçado, a $65^{\circ} \mathrm{C}$, por 72 horas. Em seguida, foi realizada a pesagem dos materiais em balança eletrônica de precisão de $0,01 \mathrm{~g}$. Para determinação do IQD, utilizou-se o método proposto por Dickson et al. (1960), por meio da Equação 1.

$$
I Q D=\frac{M S T(\mathrm{~g})}{(A P(\mathrm{~cm}) / D C(\mathrm{~mm}))+(M S F(\mathrm{~g}) / M S R(\mathrm{~g}))}
$$

Equação (1),

em que: IQD = Índice de Qualidade de Dickson, MST = Massa de matéria seca total $(\mathrm{g}), \mathrm{AP}=$ Altura de planta $(\mathrm{cm}), \mathrm{DC}=$ Diâmetro do colo $(\mathrm{mm}), \mathrm{MSF}=$ Massa seca de folhas $(\mathrm{g})$ e MSR = Massa seca da raiz $(\mathrm{g})$.

Todas as variáveis avaliadas foram submetidas aos testes de normalidade (Lilliefors) e de homocedasticidade (Barttlet), pressupostos para a validação de suas análises de variância. No caso de efeitos significativos $(\mathrm{P}<0,05)$, para as comparações entre os tratamentos T1, T2, T3, T4 e T5, relacionados com o nível de escória, adotaram-se seus ajustes em modelos de regressão pelo método dos polinômios ortogonais. Para todos os procedimentos foi adotado um "á" igual a 0,05.

Tabela 1: Análise química dos substratos utilizados nos diferentes tratamentos para produção de mudas de pimenteira Dedo-demoça

\begin{tabular}{|c|c|c|c|c|c|c|c|c|c|c|}
\hline \multirow{2}{*}{ Tratamento } & \multirow{2}{*}{$\begin{array}{c}\text { pH em } \\
\text { água }\end{array}$} & \multirow{2}{*}{$\begin{array}{l}\text { M.O. } \\
\text { g dm }^{-3}\end{array}$} & \multirow{2}{*}{$\frac{\text { P rem }}{\text { mg L }^{-1}}$} & $\mathbf{P}$ & $\mathbf{K}$ & $\mathbf{C a}$ & Mg & $\mathbf{H}+\mathbf{A l}$ & S.B. & \multirow{2}{*}{$\begin{array}{l}\mathrm{V} \\
\%\end{array}$} \\
\hline & & & & \multicolumn{2}{|c|}{ mg.dm-3 } & & \multicolumn{3}{|c|}{$\mathrm{mmol}_{\mathrm{c}} \cdot \mathrm{dm}^{-3}$} & \\
\hline T1 (0\% Escória) & 6,9 & 23,8 & 35 & 377 & 1257 & 54,5 & 14,1 & 9 & 100,8 & 91,8 \\
\hline T2 (2,5\% Escória) & 7,1 & 22,8 & 34 & 328 & 1330 & 53,8 & 21,1 & 7 & 108,9 & 94 \\
\hline T3 (5\% Escória) & 7,2 & 21,3 & 34 & 205 & 1225 & 62,5 & 14,5 & 7,5 & 109,1 & 93,6 \\
\hline T4 (10\% Escória) & 7,4 & 24 & 34 & 81 & 1198 & 65,1 & 12,9 & 8 & 108,6 & 93,1 \\
\hline T5 (20\% Escória) & 7,5 & 20,7 & 34 & 19 & 1101 & 54,7 & 21,9 & 5,5 & 104,8 & 95 \\
\hline
\end{tabular}

* Potencial Hidrogeniônico (pH) 1:2,5; Matéria Orgânica (M.O.), oxidada por dicromato de potássio e ácido sulfúrico; Fósforo Remanescente (P rem), presente na solução em equilíbrio, obtido com $\mathrm{CaCl}_{2}$; Fósforo (P) e Potássio (K), extraídos por Mehlich; Cálcio (Ca) e Magnésio $(\mathrm{Mg})$, extraídos por $\mathrm{KCl}$; Acidez Potencial $(\mathrm{H}+\mathrm{Al})$, extraídos por acetato de cálcio; Soma de Base (S.B.) e Saturação por bases (V). 


\section{RESULTADOS E DISCUSSÃO}

Nas Figuras 1(a), 1(b), 1(c), 1(d), 1(e) e 1(f), apresentam-se a altura de parte aérea, o número de folhas, o diâmetro de coleto, a matéria seca de raiz, a matéria seca de folhas e o Índice de Qualidade de Dickson, respectivamente, em resposta à adição de níveis crescentes de escória de siderurgia na composição dos substratos.

De acordo com a Figura 1(a), verifica-se que a altura de plantas aumentou significativamente com o incremento da escória, até uma concentração de $9,62 \%$, proporcionando altura máxima de 15,14 cm. A variável número de folhas também aumentou com o incremento de escória, até uma concentração de $14,23 \%$, proporcionando o valor máximo de 9,07 unidades (Figura 1b). Para o diâmetro de coleto, o incremento de escória no substrato, até uma concentração de 8,8\%, proporcionou o valor máximo de 2,69 $\mathrm{mm}$ (Figura 1c). No caso das variáveis matéria seca de raízes (Figura 1d) e matéria seca de folhas (Figura 1e), houve um aumento até concentrações de 10 e $9,2 \%$, proporcionando valores máximos de $0,131 \mathrm{~g} \mathrm{e} 0,426 \mathrm{~g}$, respectivamente.

Segundo Marana et al. (2008), para evitar distorções provenientes do excesso de nitrogênio, por exemplo, ou do crescimento foliar em detrimento do sistema radicular, utilizam-se índices de qualidade, que são relações entre os parâmetros de crescimento. Por essa razão, o IQD destacase como um dos índices mais utilizados para avaliar a qualidade de mudas, uma vez que leva em consideração a produção da matéria seca da parte aérea, das raízes e total, a altura e o diâmetro de coleto das plantas (Dickson et al., 1960). De acordo com a Figura 1(f), observa-se que o incremento de escória no substrato proporcionou valores crescentes do IQD em mudas de pimenteira Dedo-de-moça, alcançando-se o valor máximo $(0,065)$, quando se utilizaram $11,5 \%$ de escória.

De modo geral, observa-se que todas as variáveis aumentaram com o incremento de escória, até concentrações em torno de $10 \%$ ( 8,8 a 14,23\%). Esse maior desenvolvimento das mudas nessa faixa pode estar associado à melhoria do ambiente radicular, com a neutralização da acidez do substrato e com o incremento dos teores de $\mathrm{Ca}$, $\mathrm{Mg}$, bem como com a disponibilidade de fósforo adequada, ainda presente nessa faixa (Tabela 1).

Mesmo o pH do solo estando próximo à neutralidade, para o tratamento que não recebeu a adição de escória, a adição desse subproduto promoveu a elevação do $\mathrm{pH}$ do substrato para valores superiores a 7,0. Nessas condições, a redução da acidez do solo e o incremento dos teores de Ca podem ter contribuído para o maior desenvolvimento das plantas, quanto às variáveis avaliadas. É importante ressaltar que, mesmo sendo comumente adotada como ideal a faixa de pH entre 6,0 e 6,5, de acordo com Raij (1991) há uma grande variabilidade de comportamento das espécies vegetais em relação ao $\mathrm{pH}$ do solo e aos efeitos da acidez e da alcalinidade, o que dificulta o estabelecimento de uma faixa de $\mathrm{pH}$ adequada para todas as culturas. Além disso, a disponibilidade de fósforo, nitrogênio, enxofre e boro permanece elevada até o $\mathrm{pH} 7,3$, enquanto a disponibilidade dos micronutrientes aniônicos, especialmente o molibdênio e o cloro, aumenta com a elevação do pH (Souza et al., 2007). Entretanto, para micronutrientes catiônicos, como o ferro, cobre, manganês e zinco, a disponibilidade para as plantas é reduzida com a elevação do $\mathrm{pH}$. Por essa razão, o aumento do $\mathrm{pH}$ do solo com a aplicação de escória de siderurgia, mesmo atingindo valores ligeiramente superiores a 7,0, pode ter contribuído para o melhor desenvolvimento da pimenteira Dedo-de-moça.

Em concentrações superiores de escória, verifica-se um efeito decrescente nas variáveis de crescimento e na qualidade de mudas de pimenteira Dedo-de-moça. Esse fato poderia estar associado com o decréscimo de fósforo lábil, nos substratos cujos tratamentos continham maiores concentrações de escória de siderurgia (Tabela 1).

A importância do fósforo para o desenvolvimento de mudas tem sido destacada por vários autores (Brasil \& Nascimento 2010; David et al., 2008; Saraiva et al., 2011; Silva et al., 2017). De acordo com Brasil \& Nascimento (2010), o fósforo tem grande importância para o crescimento inicial das plantas por atuar no processo de armazenamento e transferência de energia, estando diretamente envolvido na absorção ativa de nutrientes. Em trabalho realizado com mudas de mamoeiro, Saraiva et al. (2011) mostraram que o efeito positivo do fósforo aumenta a matéria seca das raízes do mamoeiro, o que deve se refletir em maior capacidade de absorção de nutrientes, graças ao maior desenvolvimento radicular. David et al. (2008) relataram que doses mais altas de fósforo proporcionaram condições para a planta absorver maior quantidade de outros nutrientes, refletindo-se, de forma positiva, em maior altura e em produção de matéria seca, do maracujá amarelo. Silva et al. (2017) concluíram que doses de 1,8; 2,70; 3,14 e $3,60 \mathrm{~kg}$ por recipiente do fósforo natural reativo, resultam em mudas de maracujá amarelo com maior desenvolvimento do comprimento da parte aérea, comprimento de raízes, comprimento total da planta, diâmetro do caule, massa úmida aérea e massa úmida das raízes. Dessa forma, acredita-se que o decréscimo do fósforo lábil nos substratos com as maiores concentrações de escória pode ter prejudicado o desenvolvimento de mudas de pimenteira Dedo-de-moça.

De acordo com a Tabela 1, verifica-se aumento do $\mathrm{pH}$ em resposta às doses crescentes de escória, indicando que a escória de siderurgia atua como corretor de acidez de solo, favorecendo assim, dentro de certos limites de $\mathrm{pH}$, maior disponibilidade de macro e de micronutrientes para as plantas. Entretanto, em 
substratos com $\mathrm{pH}$ próximo à neutralidade, como o utilizado neste trabalho (Tabela 1), a adição de escória promoveu elevação do $\mathrm{pH}$, fazendo com que a disponibilidade do $\mathrm{P}$ fosse comprometida.

A elevação do $\mathrm{pH}$, acima de certos limites, pode contribuir para a redução da disponibilidade de $\mathrm{P}$ para as plantas. Com a elevação do pH, há aumento da densidade de cargas negativas nos coloides, especialmente minerais, causado pelo efeito da acidez nas cargas dependentes de $\mathrm{pH}$ do solo. Com isso, há menor densidade de cargas positivas nos coloides (Novais et al., 2007), o que poderia significar menor adsorção de fosfatos e maior
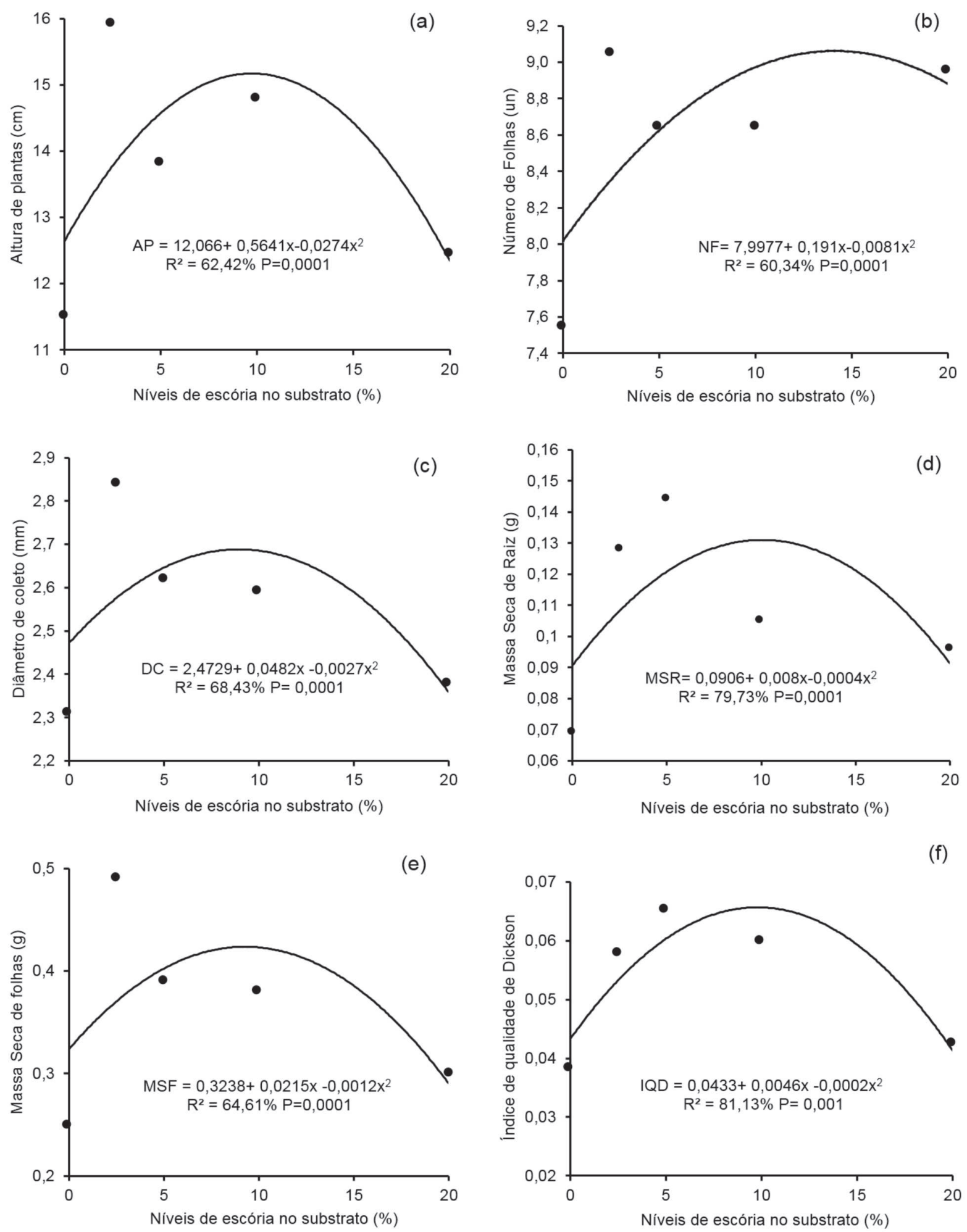

Figura 1: Altura de planta (a), número de folhas (b), diâmetro de coleto (c), massa seca de raiz (d), massa seca de folhas (e) e Índice de qualidade de Dickson (f), em função de substratos com diferentes níveis de escória de aciaria, aos 55 dias após semeadura. 
permanência do P na solução do solo, disponível para as plantas. Porém, quando a redução da densidade de cargas positivas e a permanência do $\mathrm{P}$ em solução é acompanhada do aumento do $\mathrm{pH}$ acima de 7,0 e, principalmente, com a presença de Ca na solução do solo, pode haver significativa redução da disponibilidade de $\mathrm{P}$ para as plantas, por causa da precipitação de fosfatos. De acordo com Sample et al. (1980), esse fenômeno ocorre pela ligação química do $\mathrm{P}$ e $\mathrm{Ca}$, formando fosfato tricálcico, em solos neutros ou alcalinos, dando origem a compostos pouco solúveis, o que é denominado por Malavolta (1967) de "retrogradação". É importante mencionar que, neste caso, a indisponibilidade do $\mathrm{P}$ permanece, enquanto as condições de $\mathrm{pH}$ forem desfavoráveis. Com a acidificação do solo, esses compostos P-Ca tornam-se mais solúveis e o P volta, com algumas restrições, a estar disponível para as plantas na solução do solo.

Desse modo, o uso de escória de siderurgia de aciaria pode ser uma alternativa para redução dos custos de produção de mudas, minimizando os impactos gerados pelo descarte inadequado desse resíduo pelo setor siderúrgico.

\section{CONCLUSÃO}

A adição em torno de $10 \%$ de escória ao substrato proporcionou os melhores resultados no crescimento e na qualidade em mudas de pimenteira Dedo-de-moça.

\section{REFERÊNCIAS}

Brasil EC \& Nascimento EVS (2010) Influência de calcário e fósforo no desenvolvimento e produção de variedades de maracujazeiro-amarelo. Revista Brasileira de Fruticultura, 32:892902

Caetano LCS, Prezotti LC, Pacheco BM \& Guarconi RC (2016) Características químicas do solo, produção de biomassa e teores de nutrientes e metais pesados em plantas de milho em função de doses de escória e de calcário. Revista Ceres, 63:879. 886 .

David MA, Mendonça V, Reis LL, Silva EA, Tosta MS \& Freire PA (2008) Efeito de doses de superfosfato simples e de matéria orgânica sobre o crescimento de mudas de maracujazeiro Amarelo. Pesquisa Agropecuária Tropical, 38:147-152.

Dickson A, Leaf A \& Hosner JF (1960) Quality appraisal of white spruce and white pine seedling stock in nurseries. The Forestry Chronicle, 36:10-13.

Filgueira FAR (2008) Novo manual de olericultura: Agrotecnologia moderna na produção e comercialização de hortaliças. $3^{a}$ ed. Viçosa, UFV. 421p.

Freitas GA, Silva RR, Barros HB, Vaz-de-melo A \& Abrahão AP (2013) Produção de mudas de alface em função de diferentes combinações de substratos. Revista Ciência Agronômica, 44:159-166

Malavolta E (1967) Manual de química agrícola - adubos e adubação. $2^{a}$ ed. São Paulo, Agronômica Ceres. 606p.

Marana JP, Miglioranza E, Fonseca EP \& Kainuma RH (2008) Índices de qualidade e crescimento de mudas de café produzidas em tubetes. Ciência Rural, 38:39-45.
Neves JMG, Silva HP \& Duarte RF (2010) Uso de substratos alternativos para produção de mudas de moringas. Revista Verde, 5:173-177.

Novais RF, Smyth TJ \& Nunes FN (2007) Fósforo. In: Novais RF, Alvarez V VH, Barros NF, Fontes RLF, Cantarutti RB \& Neves JCL (Eds.) Fertilidade do solo. Viçosa, Sociedade Brasileira de Ciência do Sol. p.471-550.

Pinto Júnior LAB, Vieira EA, Tenório JAS, Peixoto RAF \& Oliveira JR (2011) Caracterização da mistura de resíduos de granito e escória de aciaria LD. Revista Escola de Minas, 64:169174.

Prado RM, Correa MCM, Cintra ACO \& Natale W (2003) Resposta de mudas de goiabeira à aplicação de escória de siderurgia como corretivo de acidez do solo. Revista Brasileira de Fruticultura, 25:160-163.

Prado RM \& Natale W (2004) Efeitos da aplicação da escória de siderurgia ferro cromo no solo, no estado nutricional e na produção de matéria seca de mudas de maracujazeiro. Revista Brasileira de Fruticultura, 26:140-144.

Prezoti LC \& Martins AG (2012) Efeito da escória de siderurgia na química do solo e na absorção de nutrientes e metais pesados pela cana-de-açúcar. Revista Ceres, 59:530-536.

Raij B Van (1991) Fertilidade do solo e adubação. São Paulo, Agronômica Ceres. 343p.

Rossa Júnior J \& Portella KF (2012) Adição de escória de alto forno em argamassas colantes tipo AC-I. Cerâmica, 58:542548 .

Sample EC, Soper RJ \& Racz GJ (1980) Reactions of phosphate fertilizers in soils. In: Khasawneh FE, Sample EC \& Kamprath EJ (Eds.) The role of phosphorus in agriculture. Madison, American Society of Agronomy, p.263-310.

Saraiva KR, Nascimento RS, Sales FAL, Araújo HF, Fernandes CNV \& Lima AD (2011) Produção de mudas de mamoeiro sob doses de adubação fosfatada utilizando como fonte superfosfato simples. Revista Brasileira de Agricultura Irrigada, 5:376-383.

Silva MRR, Ignário LAP \& Silva GA (2017) Desenvolvimento de mudas de maracujá amarelo em função de diferentes doses fósforo reativo. Revista de Agronegócio, 6:41-50.

Santos ER, Nunes JS, Mello AH, Knoechelmann CM, Santos RR, Espírito Santos RN \& Pinheiro AVR (2011) Produção de mudas de Paricá com escória, inoculados com fungos micorrizicos arbusculares na reabilitação de áreas degradadas. Agroecossistema, 3:83-89.

Souza DMG, Miranda LN \& Oliveira AS (2007) Acidez do solo e sua correção. In: Novais RF, Alvarez V VH, Barros NF, Fontes RLF, Cantarutti RB \& Neves JCL (Eds.) Fertilidade do solo. Viçosa, Sociedade Brasileira de Ciência do Solo. p. 471-550. 